\title{
What are the Characteristic Features of Gut Invagination in Adults?
}

\author{
Yetişkinde Barsak Invajinasyonunun Karakteristik Bulguları Nelerdir?
}

\author{
Mücahit Emet ${ }^{1}$, Fatma Tortum', Adem Karaman², Abdullah Kısaoğlu³, Murat Sarıtemur ${ }^{1}$ \\ 'Department of Emergency Medicine, Atatürk University Faculty of Medicine, Erzurum, Turkey \\ 2Department of Radiology, Atatürk University Faculty of Medicine, Erzurum, Turkey \\ ${ }^{3}$ Department of General Surgery, Atatürk University Faculty of Medicine, Erzurum, Turkey
}

\section{ABSTRACT}

Introduction: Intussusception is malengagement of the distal bowel segment into the proximal gastrointestinal tract. It is rare in adults.

Case Report: Here, we reported a 41-year-old woman with complaints of writhing abdominal pain and vomiting whose physical examination revealed varying findings. Abdominal tomography with venous contrast showed a target lesion and sausage-shaped mass that were characteristic for invagination. Exploration showed invagination of a part of the terminal ileum, $10 \mathrm{~cm}$ in length, into the ascending colon. Operation was ended with resection and anastomosis. Histopathologic examination of the specimen showed no lesion that would lead to invagination.

Conclusion: In patients with intermittent abdominal pain and vomiting, if abdominal examination shows that the tenderness changes place and if the pain does not respond to hydration and medication, the physician should suspect invagination. It is important to recognize the target lesion and sausage-shaped mass that are pathognomonic in the abdominal tomography.

Keywords: Invagination, intussusception, radiology, adult Received: 03.04.2014 Accepted: 26.06.2014

\section{ÖZET}

Giriş: Invajinasyon gastrointestinal sistemdeki proximal barsak segmentinin distaldeki barsak segmenti içine girmesidir. Yetişkinlerde nadir görülür.

Olgu Sunumu: Bu yazıda değişen batın bulguları, kıvrandırıcı tarzda karın ağrısı ve kusmayla başvuran 41 yaşındaki bir bayan hasta sunduk. Çekilen venöz kontrastlı abdominal tomografide invajinasyon için karakteristik olan target lezyon ve sosis görünümlü kitle tespit edildi. Eksplorasyonda yaklaşık $10 \mathrm{~cm}$ uzunluğundaki terminal ileum ansının, distalindeki çıkan kolon ansının içerisine invajine olduğu görüldü. Operasyonda usülünce rezeksiyon ve anastamoz yapıldı. Spesmenin histopatolojik incelemesinde invajinasyona neden olacak herhangi bir lezyon tespit edilmedi.

Sonuç: İntermittant karın ağrısı ve kusma ile gelen hastalarda batın muayenesinde hassasiyetin yeri değişiyorsa ve hidrasyon ve medikasyona cevap yoksa nadir görülen bir akut batın nedeni olan invajinasyondan şüphelenilmelidir. Bu hastaların batın CT tetkikinde patognomik olan target lezyon ve sosis görünümlü kitleyi tanımak önemlidir.

Anahtar Kelimeler: Invajinasyon, intussepsiyon, radyoloji, yetişkin

Geliş Tarihi: 03.04.2014 Kabul Tarihi: 26.06.2014

\section{Giriş}

Invajinasyon gastrointestinal sistemdeki proksimal barsak segmentinin distaldeki barsak segmenti içine girmesidir. İnvajinasyon çocukluk çağında akut apandisitten sonra en sık görülen ikinci akut batın nedeni olmakla birlikte yetişkinlerde çok nadir görülmektedir. Erişkinlerde intestinal obstrüksiyondan \%1-5 oranında invajinasyon sorumlu olup sıklıkla 60-70'li yaşlarda görülür ve sıklığı artmaktadır (1). Yetişkinde semptomlar akut, kronik veya intermitan olabilir. En sık bulgu karın ağrısıdır (\%78-100). Karın ağrısının özellikleri ile ilgili literatürde yeterli yazı yoktur. Diğer bulgular sıklık sırasına göre bulantı/kusma, ishal/konstipasyon ve rektal kanamadır (2). Bu yazıda değişen batın bulguları ve kıvrandııcı tarzda karın ağrısıyla başvuran ve batın bilgisayarlı tomografisinde (BT) patognomonik bulgular olan bir hastayı sunmayı amaçladık.

\section{Address for Correspondence/Yazışma Adresi:}

Mücahit Emet, Department of Emergency Medicine, Atatürk University Faculty of Medicine, Erzurum, Turkey.

Phone: +90 5321612776 E-mail: mucahitemet@gmail.com 


\section{Olgu Sunumu}

Kırk bir yaşındaki bayan hasta acil servise saat 18:00 civarında karın ağrısı, bulantı, kusma şikayetleri ile başvurdu. Öz ve soy geçmişinde özellik yoktu. Illaç kullanım öyküsü yoktu. Şikayetlerinin 1-2 saat önce başladığını ve ağrının gelip geçici tarzda olduğunu ifade etti. Gelmeden önce bir kaç kezyediklerini içerir tarzda kustuğunu bildirdi. Muayeneye başlamadan önce de öğürmeleri ve bir kez yediklerini içerir tarzda kusması oldu. İshali, kabızlığı ve gaitasında renk değişikliği olmadığını

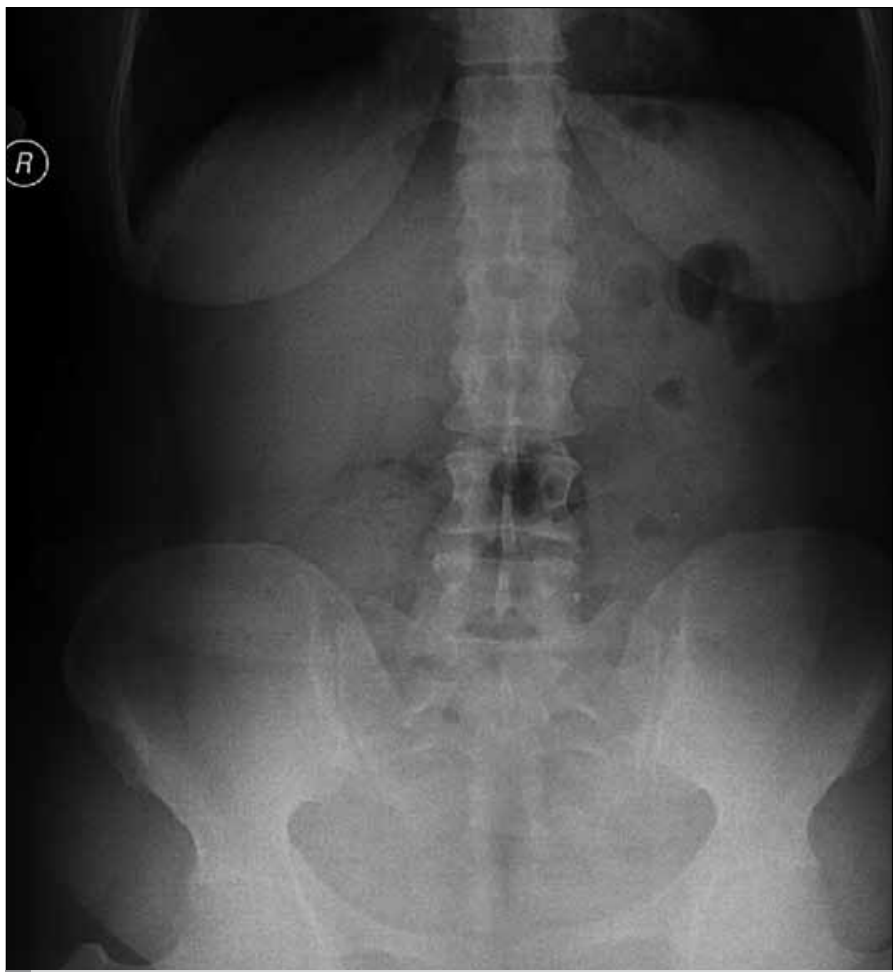

Resim 1. Ayakta çekilen direk batın grafisinde, batın sağ alt kadranda hava ile çevrelenmiş intusussepsiyon (invajinasyon) kitlesi görülüyor ifade etti. Fizik muayenede epigastrik hassasiyeti vardı. Defans ve rebound yoktu. Rektal tuşede normal vasıfta gaita mevcuttu. Hastada gastrit veya peptik ülser atağı düşünülerek damar yolu açıldı. Ranitidin 50 mg, Hiyosin-N-butil bromür 20 mg ve Metoklopramid HCL 10 mg 500 cc izotonik içinde infüzyon şeklinde verildi. Mayisi bittiğinde tekrar muayene edildi. Hastanın şikayetleri devam etmekteydi. Hasta tekrar muayene edildiğinde hassasiyetin sol üst kadran ve periumblikal olduğu tespit edildi. Defans ve rebound yine yoktu ve hasta sedyede kıvranıyordu ve ajiteydi. Hastayı kıvrandıracak derecede karın ağrısı olduğu için 0.05 mg fentanyl intravenöz yoldan puşe yapıldı. Hastaya tekrar hidrasyona başlandı. Laboratuvar sonuçlarında WBC: 10100 $\mathrm{mm}^{3} / \mathrm{dL}$, parçalı hakimiyeti mevcut (PMNL: \%74,3), hemoglobin: 12,4 mg/dL, hematokrit: \%36,4, beta-HCG negatif ve diğer tüm hematoloji ve biyokimya parametreleri normaldi. Ayakta çekilen direk batın grafisinde barsak gazlarının azaldığı (özellikle sağ üst ve alt kadranda) ve hava sıvı seviyesi olmadığı görüldü. Ayrıca ağrının etkisiyle açıklığı sağa bakan, hafif skolyoz mevcuttu. Mide gazı görülmedi (Resim 1). Hastanın değişen fizik muayene bulguları olduğu için ve karın ağrısına hidrasyon ve ilaç tedavisi ile yanıt alınamadığı için acil batın ultrasonografi uygulandı. Sonografik inceleme yeterli olmadığından abdominal BT çekildi. İntravenöz kontrastlı abdominal BT'de ileo-çekal düzeyde invajinasyon için karakteristik olan target lezyon ve sosis görünümlü kitle tespit edildi (Resim 2a, b). Hasta genel cerrahi ile konsülte edildi ve acil operasyona alındı. Eksplorasyonda yaklaşık $10 \mathrm{~cm}$ uzunluğundaki terminal ileum ansının, distalindeki çıkan kolon ansının içerisine invajine olduğu görüldü. Bu segmente usulünce rezeksiyon ve ileo-kolik anastomoz yapıldı (Resim 3). Spesmenin histopatolojik incelemesinde invajinasyona neden olacak herhangi bir lezyon tespit edilmedi. Hasta postoperatif 6. gün şifa ile taburcu edildi.

\section{Tartışma}

Yetişkindeki invajinasyon vakalarının \%8-20'si idiopatik olup invajinasyon nedeni bulunamamaktadır. Sekonder invajinasyon

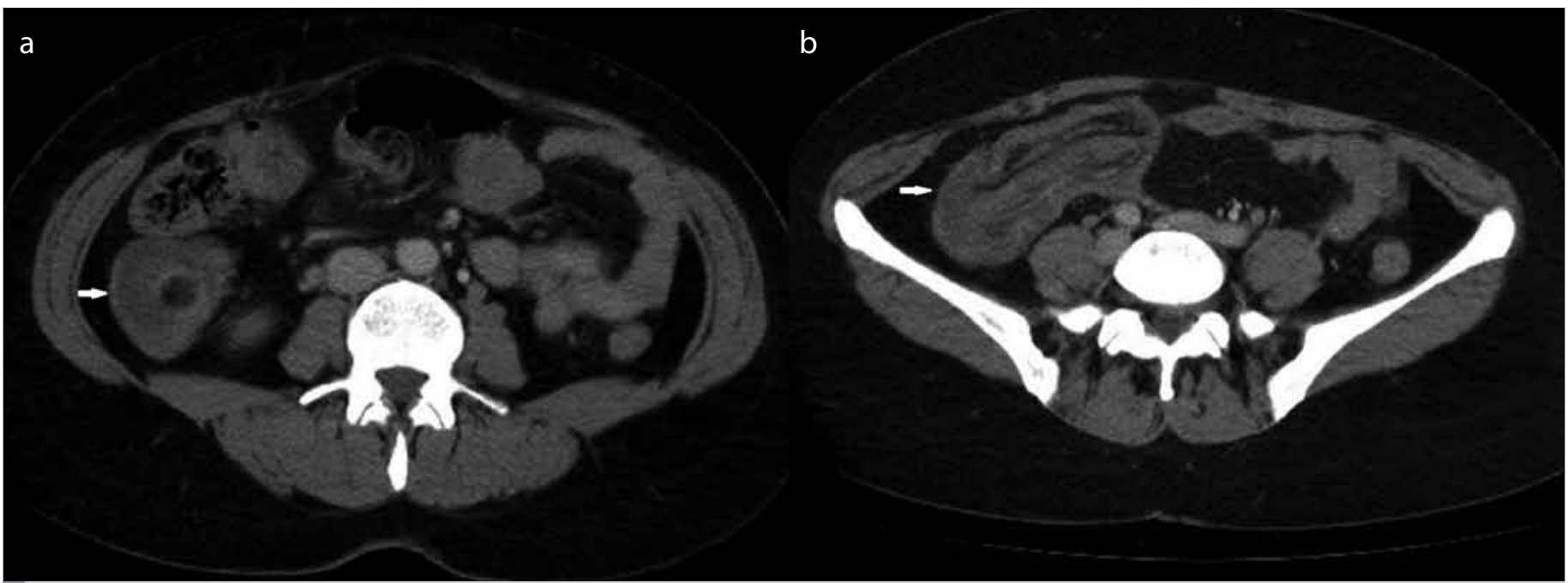

Resim 2. a, b. Batın aksiyel bilgisayarlı tomografi kesitinde çıkan kolon düzeyinde içiçe geçmiş ileal ve kolonik ansların oluşturduğu (a) hedef tahtası ("target" yada "doughnut") görünümü işareti ve çekum düzeyinde longitüdinal görünümde (b) yalancı böbrek ("pseudokidney") veya sandviç işareti 




Resim 3. Hastanın operasyon esnasında görüntülenmiş olan invajine barsak ansları

ise inflamatuar barsak hastalığı, postoperatif adezyonlar, benign ve malign lezyonlar, meckel divertikülü gibi organik lezyonlara bağlı oluşabilir (1). Zubaidi ve ark. (3) yaptığı 22 vakalık bir seride hastaların yaş ortalaması 57 bulunmuş ve hastaların \%14'ünde ince barsak invajinasyonu olduğu tespit edilmiştir. Ayrıca 2 kişide ileokolik intusepsiyon tespit edilmiş olup bu vakaların malign olduğu görülmüştür. Innvajinasyonun nedeni tipik olarak yetişkinlerde barsak yüzeyindeki patolojik bir başlangıç noktasıdır. Bu nokta vakaların yarısından çoğunda maligndir (1). Bu başlangıç noktası barsağın normal peristaltik hareketleri sırasında ileriye doğru itilir ve diğer barsak segmentinin üzerine prolabe olur (4).

Invajinasyonlar etiyolojisine göre (benign, malign, idiopatik) veya lokalizasyonuna göre (enteroenterik: ince barsak, ileo-kolik: terminal ileumun asendan kolona prolapsusu ve kolo-kolik: kalın barsak ) sınfflandırılabilir. Yetişkinlerde vakaların \%60-80'inde ince barsak tutulumu gözlenir (5). En sık görülen klinik bulgular gelip geçen karın ağrısı ve geçici parsiyel barsak obstrüksiyonunu gösteren bulantı, kusma, melena, ateş, kilo kaybı ve konstipasyondur (4). Direkt karın grafisinde distal ince barsak obstrüksiyonuna ait tipik özellikler görülür. Tanı abdominal BT ile konur. İnvajine olan barsak duvarı 2 kat barsak duvarı içerdiği için kalınlaşmış olarak görülür (6). BT'nin sagital kesitlerinde target lezyon denilen tipik görünüm mevcuttur. Axiel veya coronal kesitlerde intusepsiyon sosis benzeri kitle olarak gözükür. Çocuklarda sıkıkla görülen karın ağrısı, kitle, kanlı gaita triadı yetişkinlerde nadiren görülür (7). Barsak seslerinde azalma, karında distansiyon ve kitle palpe edilmesi fizik muayenede dikkat çeken bulgulardır (5).

Tanıda erken dönemde eş merkezli halka görüntüsü olan target lezyon tespit edilirken invajinasyonun ileri evresinde duvar kalınlaşması ve mezenter ödemine eşlik eden kitle görülür (8). Ince barsak invajinasyonu ile kalın barsak invajinasyonunu etiyolojik olarak ayıran temel faktörlerden biri ince barsak invajinasyonuna neden olan lezyonun \%90 benign özellikte olması, kolon invajinasyonunda ise altta yatan patolojinin ağırlıklı olarak malign olmasıdır (7).

\section{Sonuç}

Intermittant karın ağrısı ve kusma ile gelen hastalarda batın muayenesinde hassasiyetin yeri değişiyorsa nadir görülen bir akut batın nedeni olan invajinasyondan şüphelenilmelidir. Bu hastaların batın BT tetkikinde patognomik olan target lezyon ve sosis görünümlü kitleyi tanımak önemlidir.

Informed Consent: Written informed consent was obtained from patient who participated in this case.

Peer-review: Externally peer-reviewed.

Author Contributions: Concept - M.E., F.T., A.K., A.K., M.S.; Design - M.E., F.T., A.K., A.K., M.S.; Supervision - M.E., F.T., A.K., A.K., M.S.; Materials - M.E., F.T., A.K.; Data Collection and/or Processing - F.T., A.K., A.K.; Analysis and/or Interpretation - M.E., F.T., A.K., A.K., M.S.; Literature Review - F.T., M.S.; Writer - M.E., F.T; Critical Review - M.E., F.T., A.K., A.K., M.S.

Conflict of Interest: The authors declared no conflict of interest.

Financial Disclosure: The authors declared that this study has received no financial support.

Hasta Onamı:Yazılı hasta onamı bu olguya katılan hastadan alınmışıı.

Hakem değerlendirmesi: Dış bağımsız.

Yazar Katkıları: Fikir - M.E., F.T., A.K., A.K., M.S.; Tasarım - M.E., F.T., A.K., A.K., M.S.; Denetleme - M.E., F.T., A.K., A.K., M.S.; Malzemeler - M.E., F.T., A.K.; Veri toplanması ve/veya işlemesi - F.T., A.K., A.K.; Analiz ve/veya yorum - M.E., F.T., A.K., A.K., M.S.; Literatür taraması - F.T., M.S.; Yazıyı yazan - M.E., F.T.; Eleştirel İnceleme - M.E., F.T., A.K., A.K., M.S.

Çıkar Çatışması: Yazarlar çıkar çatışması bildirmemişlerdir.

Finansal Destek:Yazarlar bu çalışma için finansal destek almadıklarını beyan etmişlerdir.

\section{Kaynaklar}

1. Marinis A, Yiallourou A, Samanides L, Dafnios N, Anastasopoulos G, Vassiliou I, et al. Intussusception of the bowel in adults: a review. World J Gastroenterol 2009; 15: 407-11. [CrossRef]

2. Cera SM. Intestinal intussusception. Clin Colon Rectal Surg 2008; 21: 106-13. [CrossRef]

3. Zubaidi A, Al-Saif F, Silverman R. Adult intussusception: a retrospective review. Dis Colon Rectum 2006; 49: 1546-51. [CrossRef]

4. Gayer G, Zissin R, Apter S, Papa M, Hertz M. Pictorial review: adult intussusception-a CT diagnosis. Br J Radiol 2002; 75: 185-90. [CrossRef]

5. Çalık A, Topaloğlu S. İnce Barsak Tıkanıklıkları, Erişkinde Invajinasyon. In Ertekin C, Güloğlu R, Taviloğlu K, eds. Acil Cerrahi. Nobel Tıp Kitabevleri; 2009. p.365-67.

6. Mullan CP, Siewert B, Eisenberg RL. Small bowel obstruction. Am J Roentgenol 2012; 198: 105-17. [CrossRef]

7. Martín-Lorenzo JG, Torralba-Martinez A, Lirón-Ruiz R, Flores-Pastor B, Miguel-Perelló J, Aguilar-Jimenez J, et al. Intestinal invagination in adults: preoperative diagnosis and management. Int J Colorectal Dis 2004; 19: 68-72. [CrossRef]

8. Byrne AT, Geoghegan T, Govender P, Lyburn ID, Colhoun E, TorreggianiWC. The imaging of intussusception. Clin Radiol 2005; 60: 39-47. [CrossRef] 